\title{
Linfocentros de la cabeza y cuello del carpincho
}

\author{
Cao, J.A.; Bode, F.F.; Resoagli, J.M.; Millán, S.G.; Resoagli, E.H. \\ Cátedra de Anatomía Comparada Primera Parte, Facultad de Ciencias Veterinarias, UNNE, Sargento \\ Cabral 2139, Corrientes (3400), Argentina. Tel 03783-425753, E-mail: anato1@vet.unne.edu.ar.
}

\begin{abstract}
Resumen
Cao, J.A.; Bode, F.F.; Resoagli, J.M.; Millán, S.G.; Resoagli, E.H.: Linfocentros de la cabeza y cuello del carpincho. Rev. vet. 20: 2, 135-137, 2009. El presente trabajo forma parte de un proyecto cuyo objetivo es estudiar la anatomía del sistema linfático del carpincho (Hydrochoerus hydrochaeris). En esta comunicación se abordará el número, forma y tamaño de los linfocentros de cabeza y cuello, así como sus relaciones con las estructuras vecinas. Se disecaron diez cadáveres de carpinchos y los hallazgos se documentaron fotográficamente. En la región de la cabeza se hallaron los nódulos linfáticos mandibular y parotídeo, en tanto que en el cuello se evidenciaron los nódulos linfáticos cervicales (superficial, profundo craneal, profundo medio y profundo caudal). La disposición de estos linfonódulos es semejante a la de la especie porcina, aunque no se observaron nódulos linfáticos retrofaríngeos. Se espera que la localización de los linfonódulos sea útil para valorar la aptitud de la carne de $H$. hydrochaeris destinada al consumo humano.
\end{abstract}

Palabras clave: Hydrochoerus hydrochaeris, anatomía, linfocentros, cabeza, cuello.

\begin{abstract}
Cao, J.A.; Bode, F.F.; Resoagli, J.M.; Millán, S.G.; Resoagli, E.H.: Head and neck lymphocenters of capybara (Hydrochoerus hydrochaeris). Rev. vet. 20: 2, 135-137, 2009. Aim of this assay is to study the anatomy of the lymphatic system of the capybara (Hydrochoerus hydrochaeris). Number, shape and size of head and neck lymphocenters, as well as their relationships with the neighboring structures, are described in this work. Ten capybara cadavers were dissected and findings were documented photographically. Mandibular and parotid lymph nodes were found in the head, and cervical lymph nodes (superficial, deep cranial, deep half and deep flow) were found in the neck. Disposition of these lymph nodes is similar to that of the swine, although retropharyngeal nodes were not observed. It is expected that lymph nodes localization will be useful to value the aptitude of $H$. hydrochaeris meat for human consumption.
\end{abstract}

Key Words: Hydrochoerus hydrochaeris, anatomy, lymphocenters, head, neck.

\section{INTRODUCCIÓN}

El carpincho (Hydrochoerus hydrochaeris) constituye una importante especie faunística, no solo por ser la de mayor tamaño en el orden de los grandes roedores, sino por su repercusión económica debido a la utilización de su carne y cuero. Desde hace algunos años en la Provincia de Corrientes (Argentina) se practica su cría en cautiverio con fines comerciales. Tales explotaciones requieren que sus productos finales, especialmente la carne, sean liberados al consumo en condiciones sanitarias apropiadas, por lo cual resultan trascendentes

PI 23 SEGCYT-UNNE

Recibido: 31 julio 2009 / Aceptado: 14 setiembre 2009 la inspección bromatológica y el conocimiento de la ubicación de los nódulos linfáticos ${ }^{2,5}$.

La bibliografía consultada sobre anatomía de $H$. hydrochaeris reporta conocimientos sobre las estructuras de los órganos contenidos en la cavidad abdominal y aparato reproductor, no habiéndose localizado publicaciones que hagan referencia a las estructuras anatómicas del sistema linfático ${ }^{3,4}$.

El objetivo del presente trabajo fue conocer la situación, forma, tamaño y relaciones de los nódulos linfáticos de la región de la cabeza y cuello de carpinchos provenientes del Zoológico de la Dirección de Fauna y Flora de la Provincia de Corrientes y del Criadero Experimental de Carpinchos INTA-Mercedes (Corrientes, Argentina). 


\section{MATERIAL Y MÉTODOS}

Se utilizaron diez cadáveres de ejemplares adultos de H. hydrochaeris de ambos sexos. Colocados los cuerpos en posición decúbito lateral se procedió a desplazar la piel y efectuar la disección de las diferentes estructuras de las regiones cefálica y cervical. Los linfocentros fueron valorados por su número y caracteres morfométricos como tamaño, forma y relaciones con las estructuras vecinas. Los datos se obtuvieron por observación directa de los preparados anatómicos y mediciones con regla milimetrada. Tales medidas fueron procesadas estadísticamente para obtener media

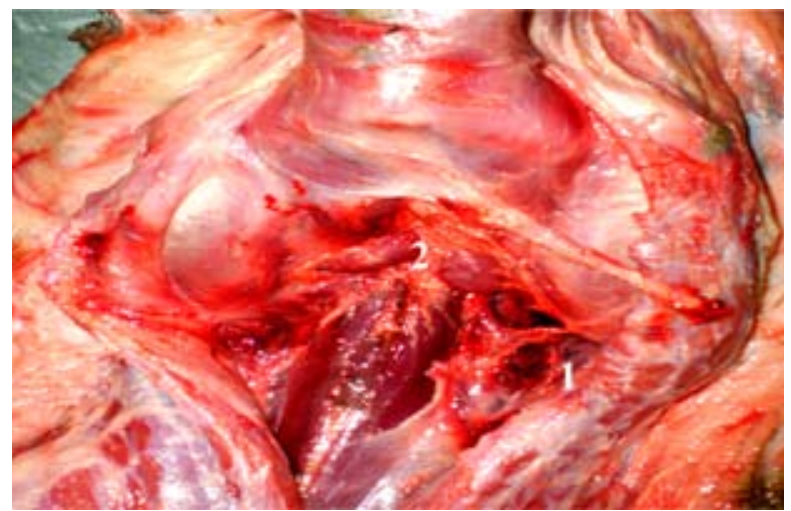

Figura 1. Glándula Mandibular (1) y nódulos linfáticos mandibulares (2).

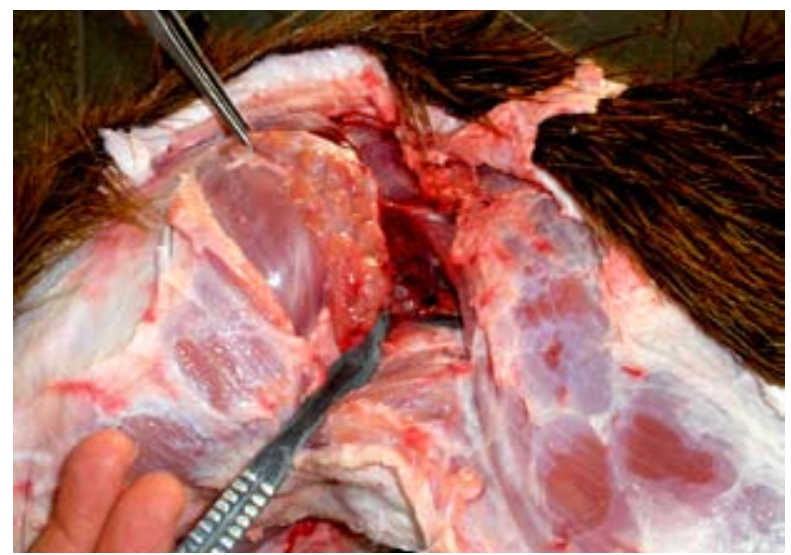

Figura 2. Nódulo parotídeo.

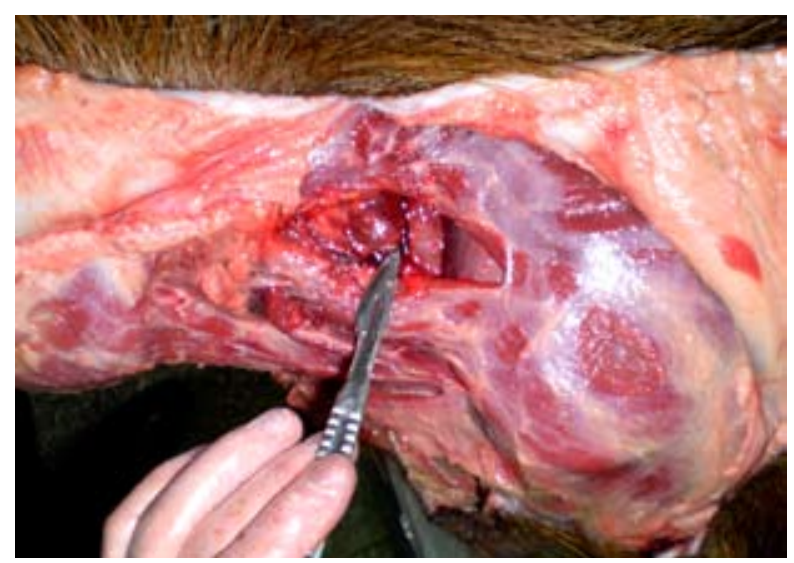

Figura 3. Nódulo linfático cervical superficial. aritmética y desviación estándar. Los hallazgos fueron documentados fotográficamente.

\section{RESULTADOS Y DISCUSIÓN}

Nódulos linfáticos mandibulares (Figura 1): 1 a 2 nódulos ovoides, de 19,5 $\pm 1,2 \mathrm{~mm}$ de largo por 14,8 \pm $0,9 \mathrm{~mm}$ de ancho. Se encuentran situados en el espacio intermandibular, en rostral de la glándula mandibular, ventralmente de la laringe y cubiertos por el músculo cutáneo facial.

Nódulo linfático parotídeo (Figura 2): pequeño, del tamaño de un grano de maíz, su longitud media fue de 4,97 $\pm 0,71 \mathrm{~mm}$ y está situado en ventral de la unión temporo mandibular, sobre el borde caudal de la mandíbula, cubierto por la glándula parótida.

Nódulos linfáticos cervicales superficiales (Figura 3): dos a tres nódulos de forma ovoide, de 20,6 $\pm 1,3$ $\mathrm{mm}$, situados en proximal de la unión escápulo humeral, sobre el borde craneal del músculo pectoral preescapular, cubiertos por el músculo braquiocefálico, entre éste y el músculo serrato cervical, en el trayecto de la vena cervical superficial.

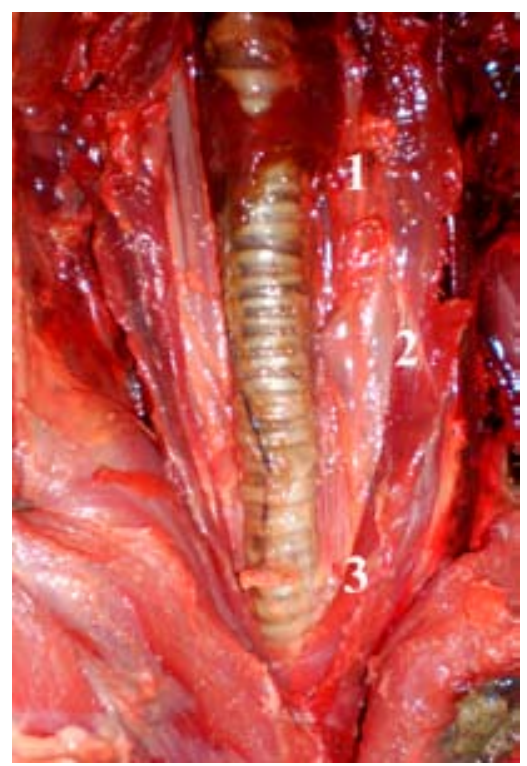

Figura 4. Nódulos cervicales: profundo craneal (1), profundo medio (2) y profundo caudal (3).

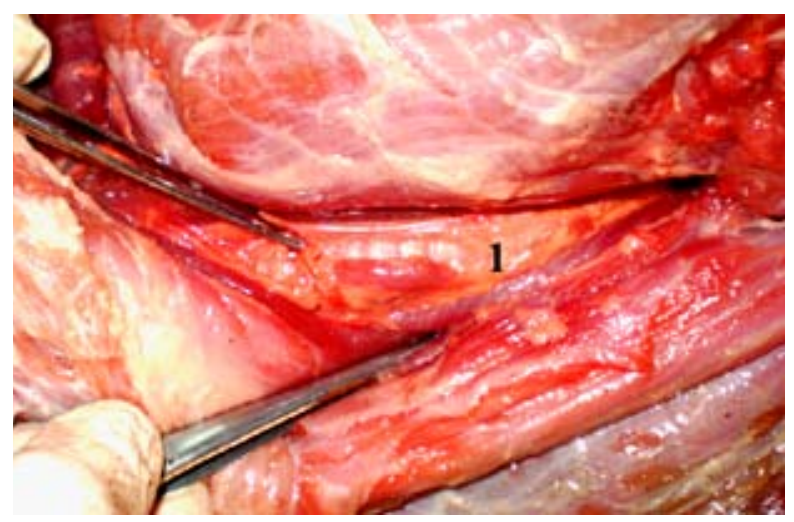

Figura 5. Nódulo cervical profundo medio. 
Nódulos linfáticos cervicales profundos craneales (Figura 4): son dos pequeños nódulos cuya dimensión promedio fue de 4,90 $\pm 0,61 \mathrm{~mm}$, situados en la celda parotídea lateralmente a la laringe, cubiertos por el borde caudal de la glándula parótida.

Nódulos linfáticos cervicales profundos caudales (Figura 4): son dos nódulos pequeños, de 4,35 $\pm 0,49$ $\mathrm{mm}$ de longitud, situados en la cara ventral de la tráquea, a nivel del XIV anillo traqueal, cubiertos por los músculos esternohioides y esternotiroides. Durante la disección no se observaron nódulos linfáticos retrofaríngeos.

Nódulos linfáticos cervicales profundos medios (Figuras 4 y 5): son constantes y de mayor tamaño que los nódulos linfáticos craneales y caudales. Se encuentran en número de dos, situados a los costados de la tráquea, de 19,8 $\pm 1,1 \mathrm{~mm}$ de longitud por 6,80 $\pm 0,64$ $\mathrm{mm}$ de ancho, a nivel del tercio medio del cuello, en el trayecto de la arteria carótida común, cubiertos por tejido conjuntivo y rodeados de tejido adiposo.

Para los linfocentros de cabeza y cuello de otras especies de consumo, resaltan los estudios realizados en porcinos, en los cuales se describen ganglios linfáticos mandibulares, retrofaríngeo y parotídeo para la cabeza y nódulos linfáticos cervicales superficiales y profundos en la región del cuello ${ }^{1}$. Las estructuras observadas en cabeza y cuello de carpinchos se asemejan en general a las descriptas para los porcinos, con excepción de los linfocentros retrofaríngeos.
Se estima que la ubicación, forma y tamaño de los ganglios estudiados asumirán importancia al momento de determinar la aptitud sanitaria de la carne y subproductos de carpincho destinados al consumo humano 2,5 .

Se concluye que las estructuras linfáticas de la región de cabeza y cuello de H. hydrochaeris no difieren mayormente de las descriptas para la especie porcina.

\section{REFERENCIAS}

1. Getty R. 1982. Anatomía de los animales domésticos, $5^{\circ}$ ed., Interamericana, México, p. 1481-1486.

2. Mayer HF. 1984. Bromatología, Ed. Impresiones UNNE, Resistencia (Argentina), p. 46-83.

3. Mendoza TH. 1977. Tórax del chigüire (Hydrochoerus hydrochaeris hydrochaeris), cavidad, análisis y topografía de órganos, trayectos vasculonerviosos. Trabajo de Ascenso, Univ. Central Venezuela, $45 \mathrm{p}$.

4. Ojasti J. 1973. Estudio biológico del chigüire o capiba$r a$, Ed. Fondo Nacional de Investigaciones Agropecuarias, Caracas (Venezuela), $27 \mathrm{p}$.

5. SENASA. 1968. On line: www.senasa.gov.ar/archivos/File/ File753-capitulos.pdf. Reglamento de inspección de productos, subproductos y derivados de origen animal (Decreto Ley 4238/68). 